\title{
Robot-assisted surgery in children: current status
}

\author{
C. K. Sinha $\cdot$ M. Haddad
}

Received: 16 September 2007 / Accepted: 5 December 2007 / Published online: 4 January 2008

(C) Springer London 2007

\begin{abstract}
The horizon of robotic paediatric surgery has grown in leaps and bounds with advances in technology. The aim of this study was to analyse the extent of robotic involvement in paediatric surgical practice. A systematic database search was performed. Data about children who had undergone robot-assisted procedures were reviewed retrospectively from all published reports up to October 2007. Success rates were defined in term of completion of the procedures, their complications, and the time taken. These results were further studied in comparison with the procedures performed by open and laparoscopic methods. A total of 31 studies were identified describing 566 patients. Of these, four studies were case control, comparing with either laparoscopic or open procedures, one study was a prospective trial, and the rest of the studies were either case reports or series. The most common robotic system used was the da Vinci (23 studies) followed by the Zeus (four studies). The mean age of the children was 8.3 years. The commonest operation was pyeloplasty (141 cases), followed by fundoplication (122 cases) and patent ductus arteriosus ligation (50 cases). The mean operation time for robot-assisted pyeloplasty was $221 \mathrm{~min}$ (open pyeloplasty $214 \mathrm{~min}$ ). The mean operation times for fundoplication were robotic, $170 \mathrm{~min}$, laparoscopic, $158 \mathrm{~min}$, and open, $121 \mathrm{~min}$. The mean operation times for patent ductus
\end{abstract}

This paper was presented at the Annual Conference of IPEG (International Pediatric Endosurgery Group) in Buenos Aires, Argentina, 2007.

C. K. Sinha $\cdot$ M. Haddad $(\bowtie)$

Department of Paediatric Surgery,

Chelsea and Westminster Hospital, London SW10 9NH, UK

e-mail: m.haddad@imperial.ac.uk

C. K. Sinha

e-mail: cksinha@btinternet.com arteriosus ligation were $166 \mathrm{~min}$ (robotic) and $83 \mathrm{~min}$ (open). Overall conversion rate for all paediatric robotic procedures was $4.7 \%$ and complications ranged from 0 to $15 \%$. For robotic fundoplications the conversion and complication rates were 0.8 and $3.3 \%$, respectively. For robotic pyeloplasties the conversion and complication rates were 2.1 and 3.5\%, respectively. Many other major operations were performed successfully. All studies recommended robotic procedure as safe and feasible. Currently, the most common robotic operations in practice are pyeloplasties and fundoplications. Most of the authors concluded that, despite taking more time, robotic surgery enables more refined hand-eye coordination, superior suturing skills, better dexterity, and precise dissection with minimal conversion and complication rates. The widespread acceptance of this technology largely depends on solving the issues: learning curve; suitable machine size for neonates and infants; ensuring efficacy and safety in all operations; and, most importantly, making this procedure cost effective, so as to cater for the needs of most, if not all, children.

Keywords Children $\cdot$ Robotic $\cdot$ Paediatric surgery

\section{Introduction}

The term "robot" was coined by Karel Capek, a Czech playwright in 1921 in his play "Rossom's Universal Robots". Taken from the Czech "robota", "robot" means forced labour, and a robot is a dumb machine performing menial, repetitive tasks. In comparison with that era, present day robots have evolved into highly intelligent machines [1-3]. At present, there is no randomized control trial of experience with robotic surgical systems in paediatric surgery. Most of the evidence is either case series or case reports 
(level-4 evidence-based medicine). The aim of this study was to analyse the current status of robotic involvement in children's surgery and generate a higher level of evidence.

\section{Materials and methods}

A systematic database search was performed. Data from children who underwent robot-assisted procedures were reviewed retrospectively from all published reports until October 2007. Data were classified into three groups: paediatric general surgery, paediatric urology, and paediatric cardiothoracic surgery. The main emphasis was to analyse the current success rate of robotic surgery in children in terms of completion of the operations, complications, and time taken. These parameters were further studied in comparison with procedures performed by open and laparoscopic methods.

\section{Results}

A total of 31 studies were identified describing 566 patients ( 513 were operated by the robotic method and 53 by either laparoscopic or open procedure in the comparative studies). Out of those, 11 studies [4-14] were in the general paediatric category (274 cases). One study [15] described both general and urology procedures. Thirteen studies [16-28] described paediatric urology operations (204 cases) and six studies [29-34] were in the paediatric cardiothoracic category (88 cases). Four studies were case control comparing robotic with either laparoscopic or open procedures, one study was a prospective trial, and the rest of the studies were either case reports or case series. The commonest robotic system used was the daVinci ( 23 studies) followed by the Zeus (four studies); one study used an AESOP robotic system and three studies did not mention the robotic system used. In one study describing 144 cases of fundoplication the AESOP robotic system was used only for telescopic assistance but operative procedures were done by a conventional laparoscopic method, so these results were excluded from our study [35]. The overall mean age of children undergoing robotic operations was 8.3 years. The commonest robotic operation performed in the paediatric age group was pyeloplasty (141 cases). Two studies were case control comparing robotic pyeloplasty with an open procedure [23, 24]. The overall mean operation time for robot-assisted pyeloplasty was $221 \mathrm{~min}$, which was comparable with that of open pyeloplasty ( $214 \mathrm{~min}$ ). Conversion to an open procedure was required in $2.1 \%$ of cases and the complication rate was $3.5 \%$. In paediatric general surgery, fundoplication was the commonest (122) operation performed. The mean operation times for fundoplication were
$170 \mathrm{~min}$ for robotic, $158 \mathrm{~min}$ for laparoscopic, and $121 \mathrm{~min}$ for open. Conversion was required in $0.8 \%$ of cases and the complication rate was $3.3 \%$.

In paediatric cardiothoracic surgery, six studies were found describing 88 patients. Of these, one study was a prospective clinical trial comparing 28 cases of robotic ligation of patent ductus arteriosus with that of 28 cases of thoracoscopic ligation [29]. There were no differences in outcome but robotic procedures took almost twice as long as open procedures and conversion to an open procedure was required in $2 \%$ of cases.

Most of the authors concluded that, despite taking more time, robotic surgery enables more refined hand-eye coordination and superior suturing skills.

\section{Discussion}

Although robots are doing highly skilled tasks in industry, their role in the surgery is still developing; even now, however, has taken the surgical profession by storm. The first report of paediatric robotic surgery, published by Gutt and Heller in 2002, described successful completion of fundoplication, cholecystectomy, and salpingoophorectomy using the da Vinci robotic system [4, 5]. In 2003, Luebbe et al. [6] reported a series of 20 cases using the da Vinci system. These cases included fundoplication, cholecystectomy, splenectomy, diaphragmatic hernia, and urachus resection. The mean age in that series was 8.4 years and the console operating time was $93 \mathrm{~min}$. In the same year, Ostlie et al. [35] published a series of 144 fundoplication using AESOP robotic telescopic control through a single umbilical cannula. Other instruments were a conventional laparoscopic instrument, placed through a direct stab wound into abdomen. The mean age in that series was only 23.9 months with the youngest child being three weeks old. The mean operating time was $90 \mathrm{~min}$, which decreased further with experience. There was one conversion due to inadequate oxygenation and three patients required re-do fundoplication due to migration of wrap into the thorax. Although the Zeus robotic system is no longer produced, it has been used successfully by many surgeons performing fundoplication, cholecystectomy, Heller's myotomy, and Morgagni hernia repair [7, 9, 13]. The Zeus Microwrist system allowed the use of smaller instruments and endoscopes. The small hand allowed surgeons more space to work. Increased tissue dexterity and easier knot tying were added advantages. In a case controlled study, Lehnert et al. found the time for robotic Thal semi-fundoplication to be $129 \mathrm{~min}$, compared with $127 \mathrm{~min}$ by the laparoscopic approach [11]. The authors' experience was that preparation of the hiatal region was $34 \%$ faster with robotics but the time saved in this preparation was counterbalanced by 
robot set-up time. In a case-controlled study Anderberg et al. [12] compared robotic, laparoscopic, and open fundoplications and reported that open procedures were the fastest (mean time $=121 \mathrm{~min}$ ) followed by laparoscopic procedures (mean time $=189 \mathrm{~min}$ ) and then robotic (mean time $=213 \mathrm{~min}$ ). They concluded that despite taking more time, robotic surgery enabled more refined hand-eye coordination and superior suturing skills. By 2007, robots had established a more secure position in paediatric surgery (with a number of publications and more complex procedures to their credit) [13-15]. Klein et al. [13] published a series of 57 cases of fundoplications, cholecystectomies, splenectomies, and other major procedures. They mentioned the conversion rate as 5\% and there was no complication related to the robotic procedures. Meehan et al. [14] reported a large, interesting, series of 100 cases using the da Vinci robotic system. The youngest patient in that series was one day old and $11 \%$ of the procedures were thoracoscopic. The conversion rate in this series was $13 \%$. Almost all types of operation (including Kasai, proctocolectomy with pull-through, duodenal atresia, and lung lesion resection) were performed in this series. In the UK one centre recently published its early experiences of 50 procedures [15]. Of these, 26 were paediatric general surgery and the other 24 were urology. The mean age was 10.2 years and the mean times required for fundoplications and pyeloplasties were 161 and $214 \mathrm{~min}$, respectively. Other major procedures successfully performed were nephroureterectomy, nephrectomy, splenctomy, re-do rectal mobilization, and cholecystectomy. Overall conversion and complication rates were 6 and $4 \%$, respectively. To achieve full potential, further experience was recommended.

In paediatric urology, Peters et al. [16] were the first authors to publish a review article in 2003, mentioning successful completion of various complex urological procedures, for example nephrectomy, pyeloplasty, antireflux surgery, appendicovesicostomy, redo-megaureter, pyelolithotomy, and excision of a large Müllerian remnant. The author emphasized the need for development of a dedicated team approach to robotic surgery. In 2004, Padraza et al. $[17,18]$ reported successful completion of appendicovesicostomy in a seven year old boy and a bilateral heminephrectomy in a four year old girl. Although operating time was quite long, the authors concluded that the robotic interface facilitated dissection of the hilum and vessels of the kidneys. In 2005, two studies were reported describing 12 cases of pyeloplasty using the da Vinci system. The authors noticed a great advantage in intracorporeal suturing, precise dissection, and handling of the tissues $[19,20]$. Over the years, robotic pyeloplasty has become more popular and two case-control studies were published in 2006 [22, 23]. Lee et al. compared 33 cases of robotic pyeloplasties with 33 cases of open procedures and came to a conclusion that robotic surgery is safe and technically feasible. One benefit was a significantly shorter hospital stay. The longer operation times in the robotic group became nearly equal to the open surgery group's time in the later part of the study [23]. Similarly, Yee et al. [22] compared eight cases of robotic pyeloplasty with a similar number of open procedures. Robotic pyeloplasty had a $100 \%$ success rate but the operating time was significantly longer $(P=0.03)$. However, the disadvantages were lack of tactile sensations and higher cost. In 2007, Oslen et al [28] reported a series of 65 pyeloplasties using the da Vinci robotic system. The mean age was 7.9 years and the mean operation time was $143 \mathrm{~min}$. Conversion was required in $1.5 \%$ of cases and complications were seen in $6 \%$ of cases. Many other urological procedures (e.g. ureteropelvic junction reconstruction, ureteric reimplantation, pyelolithotomy, and Mitrofanoff) were performed successfully by various authors [17, 18, 21, 24, 27].

In cardiothoracic surgery, Le Bret et al. [29] were the first to report a prospective clinical trial of 56 paediatric patients comparing robotic and thoracoscopic patent ductus arteriosus repairs. An equal number of children were assigned to both groups. The groups were more or less similar, except the children in the robotic group were younger (mean age 20 months) than those in the thoracoscopic group (mean age 33 months). There were no significant differences in the complications, except that one robotic operation required conversion and the robotic procedure took twice as long as the open procedure. Other studies also mentioned successful repairs of patent ductus arteriosus, vascular rings, atrial septal defects, and right aortic arch variants [30-34].

\section{Conclusion}

Robotic pyeloplasties and fundoplications have established their place in paediatric surgical practice. Initial results are encouraging, with a decrease in operation times with experience. Almost all paediatric surgical operations have been performed successfully with a small percentage of conversions and complications. Most of the studies have found that robotic surgery enables more refined hand-eye coordination, superior suturing skills, better dexterity, and precise dissection. The initial cost is an important issue affecting widespread use. As the learning curve is steep, the use of robotics in simple and common cases also will make the whole team more acquainted with the system, hence reducing set-up and operating times and cost. The ultimate acceptance of this technology will depend on issues such as size, efficacy, and safety of machines suitable even for neonates and infants. A well-structured robotics programme could be of great help in making this system a success. 


\section{References}

1. Satava RM (2002) Surgical robotics: the early chronicles: a personal historical perspective. Surg Laparosc Endosc Percutan Tech 12:6-16

2. Felger JE, Nifong L (2002) The evolution of and early experience with robot assisted mitral valve surgery. Surg Laparosc Endosc Percutan Tech 12:58-63

3. Lanfranco AR, Castellanos AE, Desai JP et al (2004) Robotic surgery: a current perspective. Ann Surg 239:14-21

4. Gutt CN, Markus B, Kim ZG et al (2002) Early experiences of robotic surgery in children. Surg Endosc 16:1083-1086

5. Heller K, Schaeff B, Beyer PA et al (2002) Use of the robot system da Vinci for laparoscopic repair of gastro-oesophageal reflux in children. Eur J Pediatr Surg 12:239-242

6. Luebbe B, Woo R, Wolf S et al (2004) Robotically assisted minimally invasive surgery in a pediatric population: initial experience, technical considerations, and description of the da Vinci Surgical System. Pediatric Endosurg Innov Tech 7:385-402

7. Lorincz A, Langenburg S, Klein M (2003) Robotics and the pediatric surgeon. Curr Opin Pediatr 15:262-266

8. Mariano ER, Furukawa L, Woo RK et al (2004) Anesthetic concern for robot-assisted laparoscopy in an infant. Anesth Anal 99:1665-1667

9. Knight CG, Gidell KM, Lanning D et al (2005) Laparoscopic Morgagni hernia repair in children using robotic instruments. J Laparoendosc Adv Surg Tech 15:482-486

10. Woo R, Le D, Albanese CT et al (2006) Robot-assisted laparoscopic resection of a type I choledochal cyst in a child. J Laparoendosc Adv Surg Tech 16:179-183

11. Lehnert M, Richter B, Beyer PA et al (2006) A prospective study comparing operative time in conventional laparoscopic and robotically assisted Thal emifundoplication in children. J Pediatr Surg 41:1392-1396

12. Anderberg M, Kockum CC, Arnbjornsson E (2007) Robotic fundoplication in children. Pediatr Surg Int 23:123-127

13. Klein MD, Langenburg SE, Lelli JL et al (2007) Pediatric robotic surgery: lessons from a clinical experience. J Laparoendosc Adv Surg Tech 17:265-271

14. Meehan JJ, Sandler A (2007) Pediatric robotic surgery: a singleinstitutional review of the first 100 consecutive cases. Surg Endosc. doi:10.1007/s00464-007-9418-2

15. Najmaldin A, Antao B (2007) Early experience of tele-robotic surgery in children. Int J Med Robotics Comput Assist Surg 3:199-202

16. Peters C (2003) Robotic assisted surgery in pediatric urology. Pediatr Endosurg Innov Tech 7:403-414

17. Pedraza R, Weiser A, Franco I (2004) Laparoscopic appendicovesicostomy (Mitrofanoff procedure) in a child using the da Vinci robotic system. J Urol 171:1652-1653
18. Pedraza R, Palmer L, Moss V, Franco I (2004) Bilateral robotic assisted laparoscopic heminephroureterectomy. J Urol 171(Pt 1):2394-2395

19. Mendez-Torres F, Woods M, Thomas R (2005) Technical modifications for robot-assisted laparoscopic pyeloplasty. J Endourol 19:393-396

20. Atug F, Woods M, Burgess SV et al (2005) Robotic assisted laparoscopic pyeloplasty in children. J Urol 174:1440-1442

21. Peter CA, Woo R (2005) Intravesical robotically assisted bilateral ureteral reimplanation. J Endourol 19:618-621

22. Yee DS, Shanberg AM, Duel BP et al (2006) Initial comparison of robotic-assisted laparoscopic versus open pyeloplasty in children. J Urol 67:599-602

23. Lee RS, Retik AB, Borer JG et al (2006) Robot assisted laparoscopic dismembered pyeloplasty: comparison with a cohort of open surgery. J Urol 175:683-687

24. Yee DS, Robert B, Klein RB, Shanberg AM (2006) Robot assisted laparoscopic reconstruction of a ureteropelvic junction disruption. J Endourol 20: 326-329

25. Passerotti C, Peter CA (2006) Robotic assisted laparoscopy applied to reconstructive surgeries in children. World J Urol 24:193-197

26. Kutikov A, Nguyen M, Guzzo T et al (2006) Robot assisted pyeloplasty in the infant-lesson learned. J Urol 176:2237-2240

27. Lee RS, Passerotti, Cendron $M$ et al (2007) Early results of robot assisted laparoscopic lithotomy in adolescents. J Urol 177:2306-2310

28. Oslen LH, Rawashdeh YF, Jorgensen TM (2007) Pediatric robot assisted retroperitoneoscopic pyeloplasty: a 5-year experience. J Urol 178:2137-2141

29. Le Bret E, Papadatos S, Folliguet $T$ et al (2002) Interruption of patent ductus arteriosus in children: robotically assisted versus videothoracoscopic surgery. J Thorac Cardiovasc Surg 123:973-976

30. Mihaljevic T, Cannon JW, del Nido PJ (2003) Robotically assisted division of a vascular ring in children. J Thorac Cardiovasc Surg 125:1163-1164

31. Suematsu Y, Mora BN, Mihaljevic T (2005) Totally endoscopic robotic-assisted repair of patent ductus arteriosus and vascular ring in children. Ann Thorac Surg 80:2309-2313

32. Miyaji K (2006) Robotic and video-assisted thoracoscopic interruption of patent ductus arteriosus. Kyobu Geka 59:661-665

33. Robinson B, Nathan M, Brown DW et al (2007) Robotic division of an unusual variant of a right aortic arch. Ann Thorac Surg 84:670-673

34. Baird CW, Stamou SC, Skipper E et al (2007) Total endoscopic repair of a pediatric atrial septal defect using the da Vinci robot and hypothermic fibrillation. Interactive Cardiovascular and Thoracic Surgery icvts: 158626

35. Ostlie DJ, Miller KA, Woods RK et al (2003) Single cannula technique and robotic telescopic assistance in infants and children who require laparoscopic Nissen's fundoplication. J Pediatr Surg 38:111-115 